\title{
Promoting agency for social-ecological transformation: a transformation- lab in the Xochimilco social-ecological system
}

\author{
Lakshmi Charli-Joseph $^{1}, \underline{\text { J.Mario Siqueiros-Garcia }}^{2}$, Hallie Eakin $^{3}$, David Manuel-Navarrete $^{3}$ and Rebecca Shelton $^{3}$
}

\begin{abstract}
Experiments to create spaces for social-ecological transformation are multiplying. These experiments aim at transcending traditional spaces for rational deliberation, planning, and participatory decision-making. We present a methodological approach for triggering the emergence of "transformation laboratories" (T-labs), which are participatory spaces where new agency is activated in relation to a stagnant sustainability challenge to generate intentional bottom-up transformations. We applied a set of participatory research tools to elicit current perceptions and foster personal involvement in transforming the ongoing urbanization of a culturally and ecologically significant historical wetland in Mexico City. Given that the emergence of T-labs as genuine bottom-up transformative spaces involves changes at multiple levels (individual, collective, and social-ecological), our approach was designed to promote a safe space that stimulates openness and personal interaction. We posit that through enabling participants to reformulate their connections to the system, to others in the system, and to themselves, the system may be transformed from the inside out. We argue that transformation, in this sense, is essentially about how changes in perception about one's own role in the system's dynamics translate into changes in agency. Our T-lab brought in 19 agents involved in the use and management of the Xochimilco urban wetland. Through a set of research tools, we elicited and presented information that helped agents to see their social-ecological position and role and to identify the practices they share with others within specific social networks and spaces of action. We argue that the process of collaboration initiated by our application of these tools and communication of their results are key for advancing initiatives that seek to create conditions for endogenous transformations.
\end{abstract}

Key Words: agency; Mexico; social-ecological systems; sustainability; transformation; transformative space; urbanization; Xochimilco

\section{INTRODUCTION}

Many parts of the developing world are facing acute socialenvironmental challenges that have proven resistant to ameliorative interventions and threaten progress toward sustainable development goals (e.g., Leach et al. 2012). The urbanization of sites of significant ecological value, and the social and environmental consequences of such urbanization, is of particular concern. While such urbanization is often a response to an unmet demand for housing, these processes of land transformation can produce risky circumstances for human habitation and erode ecosystem services provisioning. Efforts to halt urbanization or penalize settlements are often unproductive or have fueled social conflict (Moctezuma 2001). These situations, in which ecological pressure is addressed through interventions that ignore socio-cultural components, may result in increased social tension and "trapped" conditions (Eakin et al. 2016, Lade et al. 2017). The individuals in such systems often have multiple identities, roles, and needs: they may simultaneously be land owners, natural resource users (fishers, farmers), members of expanding families in need of housing, community organizers, immigrants seeking work, public officials balancing their actions to achieve both electoral support and rule enforcement, and even environmental activists. Thus, despite both grassroots and formal interventions and policy initiatives to halt urbanization, conflicting incentives, local power dynamics, and diverse needs prevent agents from coalescing around solutions and pathways forward (Barkin 1998, Mohan and Stokke 2000, Maru et al. 2012, Eakin et al. 2016). Given this complexity, many scholars have called for sustainability research and intervention approaches that support a deliberate transformation of the social-ecological system (SES): approaches that focus not on addressing the exogenous drivers of system change but rather on the internal cognitive and emotional dimensions of human agency, reflexivity, and learning in support of collective action (e.g., Ostrom 2000, 2009, Pahl-Wostl 2002, Diani and McAdam 2003, Pahl-Wostl et al. 2007, Moore and Westley 2011, Westley et al. 2011, 2013, Moore et al. 2014, Manuel-Navarrete and Pelling 2015).

Here, we describe a suite of tools that help elicit a depiction of individual agency and the social and ecological relations in which that agency is constituted and exercised. We posit that using these tools to draw agents' attention to their own agency and how it is embedded within and connected to the agency of others in an SES can be a first step toward motivating collective action. These tools are deployed in the context of an experimental intervention: a "T-lab" designed to foster deliberate change. The concept of transformation laboratories, or T-labs, has emerged as a means through which to provide interactive, participatory innovation spaces that allow for experimentation with new social-ecologicaltechnological system configurations and sustainability pathways (Olsson et al. 2014, Karpouzoglou et al. 2018). Often called laboratories (e.g., transition labs, sustainable food labs, social labs, etc.), these experiments aim at transcending traditional spaces for rational deliberation, participatory decision-making planning, and participatory development (e.g., Van der Walt et al. 2009, Hassan 2014, Heras and Tàbara 2014; Gryszkiewicz et al. unpublished manuscript, http://dx.doi.org/10.2139/ssrn.2556692). In our case, the primary objective of the T-lab was to make visible to participants the nature of their own individual and collective agency within the dynamics of the social-ecological system.

For agents (including the research team or facilitators) participating in a T-lab, the nature of the transformation that

${ }^{1}$ Laboratorio Nacional de Ciencias de la Sostenibilidad (LANCIS), Instituto de Ecología, Universidad Nacional Autónoma de México, ${ }^{2}$ Instituto de Investigaciones en Matemáticas Aplicadas y en Sistemas (IIMAS), Universidad Nacional Autónoma de México, ${ }^{3}$ School of Sustainability, Arizona State University 
might emerge is initially undefined; the focus is on the contributions of the participants and the tools and approaches that might lead to novelty and collective innovation. Agency and its mobilization is thus a critical ingredient in the T-lab process. Nevertheless, to date there have been relatively few detailed descriptions of the methodology used in support of these experiments. In particular, empirical research is required on how such interventions can foster agency to enhance the potential for novel interventions in sustainability challenges (Tschakert et al. 2016, Abson et al. 2017). Thus, here, we focus on the tool kit we employed in the first stage of our T-lab experiment in an effort to underscore how depicting the agency of individuals is useful for a process in which individual agency is the building block for collective action.

\section{Agency and social-ecological system transformation}

Although there is growing agreement on the critical role that agency plays in fostering processes of transformation (e.g., Westley et al. 2011, 2013, Moore et al. 2014, Pesch 2015), there are still empirical, methodological, and theoretical gaps in the criteria and methods that contribute to identifying and promoting agency to enhance the potential for novel interventions in sustainability challenges (Leach et al. 2012, Tschakert et al. 2016, Abson et al. 2017) and the role of supporting agency in the design of transformative spaces (Pereira et al. 2015). Agency is necessary in fostering, promoting, and implementing change (e.g., Bourdieu 1977, Giddens 1984, Emirbayer and Mische 1998, McLaughlin and Dietz 2008, Barandiaran et al. 2009, Westley et al. 2001, 2013, Pesch 2015, Vänninen et al. 2015, Di Paolo et al. 2017, Walker 2018). O'Brien and Sygna (2013), for example, argue that transformation must be conceived of as taking place in three spheres: the personal, the practical, and the political. Within the personal sphere, reflexivity, confronting one's own and collective worldviews, and making values explicit are part of a necessary process of personal transformation. The practical sphere entails people's goals and the strategies and actions they employ to achieve them. The political sphere includes the structures, institutions, and processes beyond the individual that influence system dynamics. As O'Brien and Sygna (2013) point out, although these spheres are interdependent, the interactions among them are rarely sufficiently explored in transformation efforts; agency clearly plays a critical role in such interactions.

Collective agency and action emerges from the beliefs, intentions, perspectives, values, and interactions of unique individuals in interaction, thus highlighting the importance of understanding individual agency. An agent is an individual that embodies a set of socially shared beliefs, values, and norms that justify and motivate its actions. SES dynamics are contingent on human agents' intentions toward the system, which include deliberate efforts to maintain or alter the system's emergent structures and identity (Manuel-Navarrete 2015). Thus, placing human agency at the center of social-ecological transformations highlights the intrinsic involvement of humans in emergent dynamics of SESs and the transformations of such structures.

It is a common activity in social-ecological research to request that agents depict the dynamics of the SES in which they are embedded and imagine, abstractly, how and what might influence those dynamics. It is less common to employ methods that embed agents within a system, illustrating how their existing individual and collective intentions, roles, and actions interact with their surroundings to influence ecological processes and social relations. Nevertheless, it is the collection of individuals and their interactions in a particular social-ecological domain that shape (but do not determine) the potential scope of transformation. From our perspective, agency is not given to the individual but is developed over the course of a lifetime in which the process of becoming an agent is achieved in a dynamic and coupled interaction with the social-ecological and cultural environment (Laland and O'Brien 2011). Thus, agency is emergent from a process of mutual transformation among the individual and its environment, within social networks, and with culture. This understanding of agency assumes that an agent is always a situated individual within some defined context and that this context shapes and is shaped by the individual through its practices and interactions.

A common mistake in participatory development interventions is to assume the existence of strong collective agency in local communities (Williams 2004). Participatory processes have long been critiqued in the development literature for being instruments of the utilitarian and technocratic goals of hegemonic agents or the state, rather than processes that empower participants as political agents of destinies of their own choosing (Williams 2004). The assumption that change must emerge from decentralized, local initiatives dependent on the existence of significant agency is problematic: not only are local contexts subject to politics, co-option, and competition (Williams 2004), but also the "wicked" problems that characterize most sustainability challenges feature political forces and economic interests as well as institutions that are instrumental in maintaining individuals in marginal conditions (Wood 2003).

Kothari (2001) criticizes participatory development programs as processes that further marginalize individuals and groups by instrumentalizing process outcomes for a prepackaged "development process" that they neither conceived of nor consented to. In our own fieldwork experience in Mexico and elsewhere, we have encountered local communities that are "burnt out" by disappointing "participatory" processes that delivered neither real participation nor empowerment. T-labs seek to address this cynicism directed toward the participatory process by shifting the goal of intervention explicitly from "participating in development" to enabling "collective action" and coordination. This shift is consistent with calls for interventions that open up new spaces for political action through building "political capabilities" (Williams 2004; Whitehead and Gray-Molina, unpublished manuscript, http://siteresources.worldbank.org/ INTPOVERTY/Resources/WDR/DfiD-Project-Papers/whitehea. pdf). However, T-lab interventions go beyond the political by positing that collective and individual capacities are developed through the cultivation of aware social-ecological agents (Manuel-Navarrete and Buzinde 2010). Thus, interventions are not just focused on bestowing the poor with capacity to partake in participatory arenas and processes set up or condoned by the state, but rather on cultivating capacities as social-ecological subjects, to shape (and transform) the SES of which they are already a part (Manuel-Navarrete and Pelling 2015). Aware of this challenge, our aim in the T-lab was to identify those agents who would be willing to engage in a series of social interactions, i.e., getting together with the research team and other individuals interested in social-ecological change, without knowing the endpoint of the process. 


\section{The problem space}

We apply our approach to depicting agency within the context of a specific wicked problem: the nexus of urbanization, wetland conservation, and livelihood sustainability in Xochimilco, Mexico City. The Xochimilco urban wetland ecosystem has been in a process of degradation for several decades and is currently highly contaminated from urban waste and agricultural activities and is overexploited by tourism (Mazari-Hiriart et al. 2008, Zambrano et al. 2009). The wetland is the last remnant of the pre-Hispanic wetlands and agricultural system composed of chinampas, a type of Mesoamerican agriculture consisting of rectangular raised fields to grow crops on a shallow lake, which once formed the basis of Mexico City's agricultural development.

Today, there are fewer and fewer farmers (chinamperos) who want to farm the chinampas, and thus, there is a strong incentive to urbanize the land. Urbanization, however, leads to structures that are subject to flooding and subsidence, and the lack of sewage infrastructure results in the discharge of wastewater directly into the wetland. The city government recognizes the ecological and recreational value of the wetland and has worked to attract international attention and support for its conservation. However, ineffective policies, inadequate resources, and corruption have undermined formal efforts (e.g., Wigle 2010, 2014). Both urban and agricultural residents resent the city's efforts to impose ecological regulations, whereas some environmental groups view local residents as complicit in degradation through farming practices and illegal urban construction. Other local inhabitants (some farmers, some descendants of chinamperos, some immigrants seeking housing, and some fishermen) perceive diverse causes of degradation, including urbanization, pollution, lack of interest of landowners, and lack of enforcement by officials. As a result of a diversity of conflicting incentives, agendas, and trends, some local activists have articulated that the system is trapped: there is little consensus or trusted leadership and few clear policy alternatives that would alter what many have concluded are undesirable social-ecological dynamics.

It was from within this context that we engaged local residents in the process of a T-lab with the aim of exploring alternative, though not yet identified, pathways toward social-ecological transformation. Rather than focusing on external "solutions," although these may emerge in the process of the T-lab, we focus on what individuals working together can do to accomplish their goals by making visible who is doing what, with whom, where, and why, and how participants in the T-lab think these relationships can or should change if specific outcomes are desired or attributes of values are to be preserved. In other words, we aimed to help participants (including ourselves) identify and mobilize their capabilities, roles, and responsibilities in relation to the wetland's past, present, and future.

The T-lab in Xochimilco is ongoing. Designed as a two-year process (with the potential to continue, according to the motivation and interests of the participants), the T-lab aims to be an emergent space for reflection, reframing, and the formation of new pathways for change. Phase 1 of the T-lab process was designed to accomplish the following goals: (1) make visible the manifestation of individual participants' agency in the SES by using tools that position them in the system in terms of their social relations and networks, regular activities, goals, and values within the system (i.e., the space of action); (2) develop tools that allow different individuals to describe how they perceive the system in which they are embedded; and (3) work with the participants to help them identify where they feel they have agency in the system, over what elements, and through what networks. Through achieving these goals, we aimed to depict the elements that illustrate the profile of each individual's sense of agency and what we call the space of action of each individual.

This phase is followed by a series of social interactions, or encuentros, which are meetings of the individuals who participated in phase 1 of the process, as well as the implementation of a series of activities designed to foster new insights into the SES's dynamics, the role of the participants in those dynamics, and collective pathways forward. This phase is ongoing and will not be described here.

We next describe the methods we designed and implemented to select the participants for the T-lab and elicit elements of their individual agency. In addition, we present how we visually represented these elicited elements to enhance the understanding of one's own agency and its relationship to others' agency. We then explain the results of applying these methods in the case of Xochimilco and conclude with a discussion of how these tools were received by the participants in the T-lab and what we learned from the process about mobilizing agency for sustainability transformations.

\section{APPROACH AND METHODS}

\section{Criteria for involving participants}

We recruited participants for the project by relying on key informants who had participated in former research projects in the area and on snowball sampling methods. To help identify which personal characteristics might be relevant to the process, we began with criteria on leadership and "change agents" defined within the existing sustainability literature, primarily informed by Westley et al. (2013). We modified these criteria to acknowledge the local context. In our case, we aimed for a group of participants that collectively had: (1) diverse types of knowledge about the area; (2) actionable social networks, e.g., through previous capacity-building projects, organized collective work, institutional affiliations, etc.; (3) capacity and willingness to experiment with different approaches; (4) determination and will to both conserve social-ecological attributes of the system and change the current hindering conditions; (5) some sense of attachment to the place, i.e., Xochimilco wetland; (6) experience in alternative activities, e.g. organic farming, ecotourism, ecotechnologies; (7) solidarity and empathy with respect to other group members; and (8) experience working on problems of community development and grassroots innovation.

The composition of the sample of 19 interviewees is as follows. Nine participants were from civil society: five of these were local agricultural producers from different areas and types of production, two worked in capacity-building projects in the area (tightly linked to academia), one worked in irregular settlements activism, and one was an artist. Four participants were governmental agents from the city and federal level, working in the areas of urbanization, wetland conservation and climate change, environmental enforcement and compliance, and city resilience initiatives. Three participants were academics, all 
working in the area around issues of water quality, conservation, and sustainable production schemes. Three participants were from nongovernmental organizations: one worked in rainwater harvesting techniques, one was from a local nongovernmental organization that promotes sustainable agricultural practices, and one worked in sustainable urban projects. The group was composed of participants that could act at different levels of action, i.e., from local (chinamperos) to global projects (i.e., the 100 Resililent Cities) and from within the boundaries of the wetland system and beyond its boundaries. The array of participants also included a variety of agents that covered diverse arenas of action such as political and academic.

We determined that two types of participants were needed for different roles in the project. First, agents with potential to support alliance building are crucial for affecting system change (Dorado 2005, Westley et al. 2013). These agents were identified by their sector of work, institutional affiliation, attribution, and diverse experience and knowledge (e.g., certain senior academics, policy makers from the federal government). This group acts as informants for the process, rather than being involved during the collective interactions (i.e., in phase 2). In some sense, they can be thought of as companions that accompany and support the core group initiatives. The second set of agents were invited to be more directly involved in the collaborative process and thus were selected based primarily on the criteria for and qualities of change agents. This group of individuals comprises both "outsiders" (e.g., individuals with experience working on problems of community development and grassroots innovation but not necessarily addressing the main issues in the area) and "insiders" (e.g., individuals who work and live in the area). Thus, these participants would be those who we anticipated would eventually participate in the collaborative processes we are designing to engender SES transformation.

\section{Agents' profiles and baseline}

Once potential participants were identified, we created a comprehensive profile for each one of them to capture elements of the individual's agency and present those elements back to the participant and to others. In relation to the broader T-lab process, the elements of individual agency that were captured during this initial interview were recorded as a baseline from which we could assess any changes in an individual's self-described agency. These profiles could also serve as points of reference from which collective agency could emerge: We expected to see elements of individual attributes and capacities being mobilized in collective action, and the participants to incorporate each other into their action networks through the T-lab process.

The individual profiles are composed of three main elements: a stakeholder network map (other individuals with whom a person works within the area, and the practices that connect them), a participant's perception of the system and her or his place in it, and a preliminary indication of the individual's value system. We designed specific methods for each element, as follows, and implemented them through semistructured individual interviews.

\section{The social action arena}

We used two techniques to help the interviewees identify the social and ecological space in which they were embedded within the broader SES (the social action arena). These techniques elicited the agent's social network, which, for this purpose, included the people with whom they were collaborating most frequently ("egonets") and the practices that characterized these collaborations ("action-nets"). The ego-nets and action-nets together depict what we call the social action arena, which depicts the interviewee's social capital and role in system dynamics. The interviewees' ego-nets (Crossley et al. 2015) are illustrated with three dimensions: alters composition, distance, and influence and nature of relation (Fig. 1; for details, see https://github.com/ sostenibilidad-unam/tlabs/blob/master/ANA.md).

Fig. 1. Example of an ego-net.

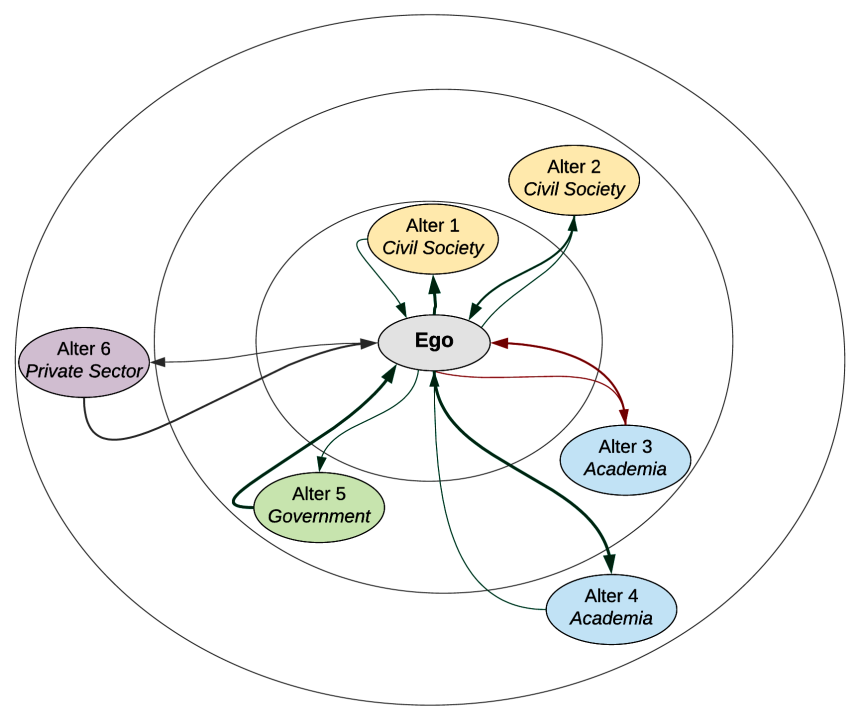

The action-net (developed by the first and second authors) is a general bipartite or two-mode directed network that is composed of two kinds of nodes: alters and practices. This network presents the alters (the same as represented in the ego-net), linked by practices, e.g., those activities through which an ego interacts with one or more alter (Fig. 2).

\section{Depiction of agents' problem space}

We used cognitive mapping-based techniques to elicit how the interviewee perceives the problems confronting the SES in which he or she is embedded in terms of the causal relationships of elements and variables that shape the system. The output of this process is an individual baseline cognitive map from which changes in perception and problem framing can be evaluated as the T-lab progresses. In our case, for example, we used cognitive maps to identify how agents perceived and conceptualized the problem of urbanization and wetland degradation in Xochimilco prior to the next phases of the T-lab interventions.

The first step was to assemble a set of core variables that we gathered from preliminary semistructured interviews with key informants, as well as from the literature review. These variables were categorized into two types: state and process variables (Table 1, Fig. 3). The core set of predefined variables represents crucial causal relationships in the Xochimilco wetland system and allowed us to compare the different cognitive maps; however, if the interviewee required it, new variables could be added to the cognitive map (for details see https://github.com/sostenibilidadunam/tlabs/blob/master/ANA.md). 
Fig. 2. Examples of action-nets for alters (A) and practices (B).

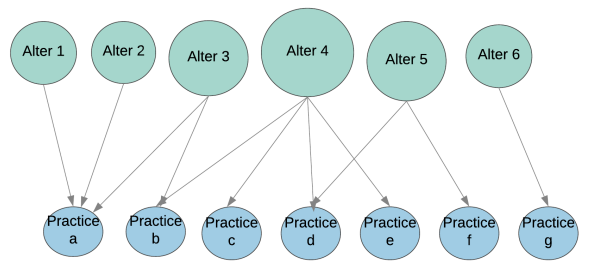

2a. Alters (by Outdegree)

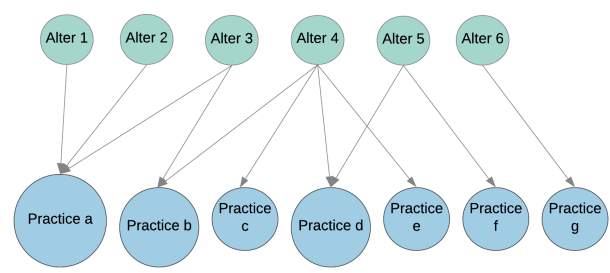

2b. Practices (by Indegree)
Table 1. List of predefined state and process variables.

\begin{tabular}{ll}
\hline \hline State variables & Process variables \\
\hline Water pollution & $\begin{array}{l}\text { Human migration (immigration } \\
\text { and emigration) }\end{array}$ \\
Water scarcity & $\begin{array}{l}\text { Population growth } \\
\text { Chinampas abandonment }\end{array}$ \\
Land subsidence & Chinampas urbanization (due to \\
Overexploitation of water & land use change) \\
resources & Wastewater discharge \\
Human health problems & Solid waste disposal \\
Irregular settlements & Loss of biodiversity \\
Regular settlements & $\begin{array}{l}\text { Intensive agricultural activities } \\
\text { (greenhouses, pesticides) }\end{array}$ \\
Inequality (due to lack of access \\
and work opportunities) & Loss of soil quality \\
Lack of infrastructure and urban & \\
services & \\
Lack of participation from civil & \\
society & \\
Lack of institutional coordination & \\
Lack of public policy & \\
implementation & \\
Young generations do not work in & \\
agriculture & \\
Loss of cultural values & \\
Lack of markets & \\
Lack of regulation of touristic & \\
activities & \\
Inappropriate livestock practices & \\
\hline
\end{tabular}

Based on the connectivity degree of the variables as well as their position in the network, we made a qualitative classification of the participants into different groups by identifying the topics of the variables in the cognitive maps. When looking at these properties, it is possible to infer a participant's understanding of the Xochimilco SES and its degradation. Thus, we defined five categories to represent the general focus of their system interpretation: agro-ecological/water, cultural, urban, governance, and urban governance. Although two or more residents may be categorized in the same group, they may have distinct (although associated) narratives on the same topic. The classification of interviewees by their primary focus of concern around the system is informative about the differences in problem framings. Interestingly, interviewees might coincide in the same focus of concern but differ in their cognitive map relevant variables. Finally, we combined all the individual cognitive maps to explore whether we could define meta-narratives among the interviewees, for example, connections among system elements that were repeated by two or more participants.
Fig. 3. Example of a cognitive map.

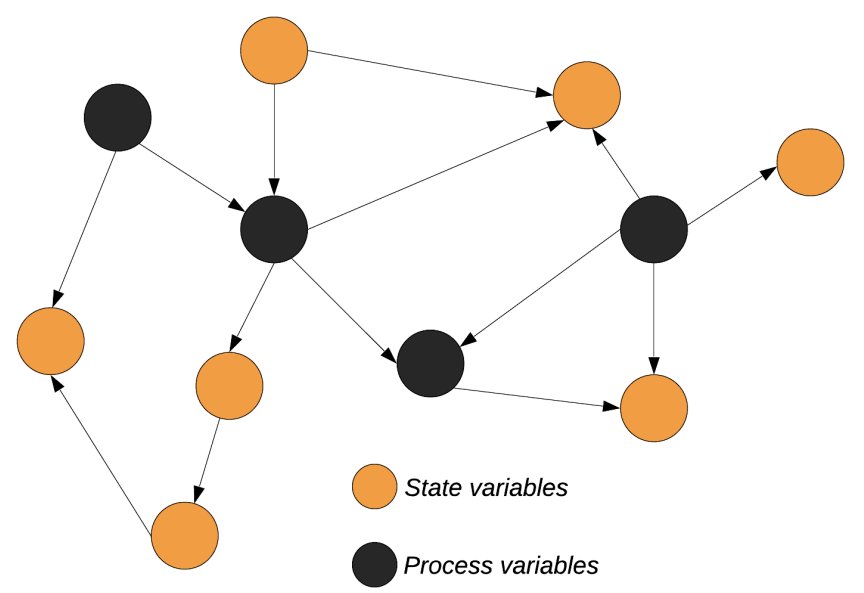

Together, stakeholder network mapping and cognitive maps comprise a methodology for depicting individual agency that we refer to as agency network analysis (ANA). Our goal is for ANA to provide a series of outputs ("maps") for participants to use as learning and reflection tools regarding how their activities and roles relate to and influence the SES. In this sense, ANA is a building block for deliberate transformation of an SES. In particular, ANA was designed to map the interviewee's social action arena in the context of the problem space as perceived by the interviewee. This is accomplished by situating the relative position and importance (centrality, betweenness-centrality, and clustering coefficient) of the alters (collaborators) to the ego (the interviewee). Critically, this method is designed to ensure that the interviewees situate themselves as agents with influence within the system, rather than as external observers. Thus, the method requests that the interviewees identify where (in relation to which variables in the cognitive map) they see their current capacity for intervention in the problem situation (e.g., in relation to which other agents, and over which system variables), with the expectation that this will empower them to act. Furthermore, ANA was also designed to facilitate self-reflection by enabling participants to describe distinct narratives about their connection to the SES, for example, in relation to other agents (ego-alters), among and across the network (alter-alter), and in relation to practices and the elements of the SES (practices-world). Such narratives refer to system elements that are represented both in the stakeholder network mapping process and in crucial elements 
of the system that the interviewee depicted through cognitive mapping. The structure of narratives is of the sort: "I, working with $\mathrm{x}$ and $\mathrm{y}$, doing $\mathrm{z}$, act on a,b,c variables of the system."

\section{Agents' value system}

To identify how each interviewee values different attributes of the SES and thus normatively frames his or her issues of concern in relation to the SES, we used Q methodology (e.g., Brown 1986, Webler et al. 2009, Zabala 2014). The objective of this activity was to explore with the interviewee how his or her activities, social interactions, and depiction of the problem situation in the SES were related to the elements and attributes of the SES that the participant valued most. We assume that the actions of any agent are in part guided by those issues that the agent perceives as relevant and valuable (Stern and Dietz 1994). In our case, we assessed how different participants perceive the role of specific meaningful attributes in key activities that take place in the wetland (around issues of conservation, degradation, urbanization, rights to land and water, among others).

Q methodology entails having the interviewee sort normative statements about a topic. For our case, a total of 15 T-lab participants were asked to sort 28 statements, ranging from statements that they most agree with (value +4 ) to statements that they most disagree with (value -4 ). The statements were extracted from previous interviews in the area and from the literature. Such statements (called Q statements) relate to four main categories: land use and property rights (four statements); patrimony, identity, and values (12 statements); ecological conditions and stressors (eight statements); and livelihoods (four statements).

All participants' sorts of statements (Q sorts) were statistically analyzed using the $Q$ methodology package for $\mathrm{R}$. This software package uses principal component analysis to find how individuals are correlated to one another based on their agreement or disagreement on particular sets of statements (Webler 2009, Zabala 2014; for details see https://github.com/sostenibilidadunam/tlabs/tree/master/qmethodology).

We obtained complete ego-nets, action-nets, and cognitive maps from 17 of the 19 individuals we interviewed, and we performed the Q methodology with 15 interviewees. Overall, we obtained 12 interviews with a complete set of maps and results from applying the $\mathrm{Q}$ method. For this reason, the analysis for the integrated instruments (ANA plus Q methodology) considered these 12 interviewees. We derived visual representations of each participant's networks and practices in the problem space that they defined through the approach described above.

Together, the stakeholder network mapping, the elicitation of individual cognitive maps of the SES, and the application of Q methodology provide a profile of the interviewee's agency and can be used as a baseline from which to evaluate change as the interviewee interacts with other participants in the T-lab in later stages of the process. In Fig. 4, we illustrate how the three different instruments are articulated to identify the conceptual elements of individual agency.

\section{RESULTS}

The results from the interviews showed that participants were different in terms of their background, sector of work, and their particular attachment to the Xochimilco SES. ANA and Q methodology showed that participants depicted themselves as attached to the area and as risk takers and innovators. They were also perceived by others as honest and trustworthy. We shared the results from our analysis of each interviewee's capacities, networks, and thus, current agency, to the respective interviewee directly, but otherwise, we kept the analyses confidential.

Fig. 4. Flowchart showing how individual agency is identified.

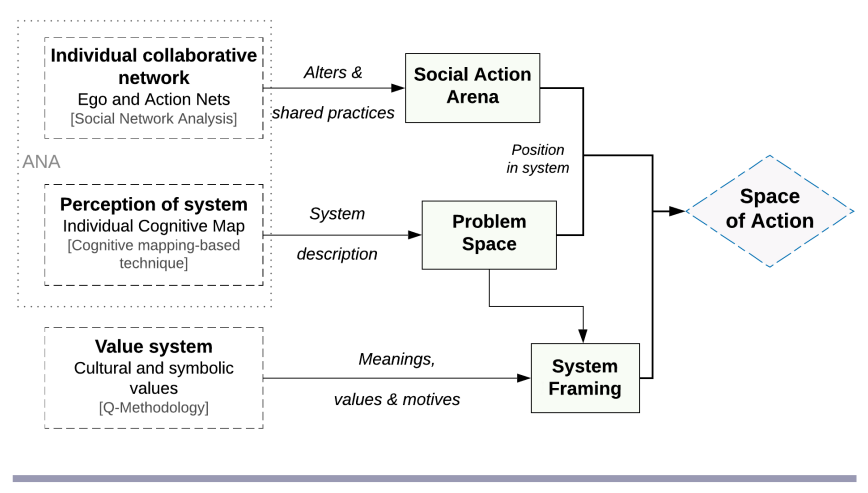

\section{The social action arena}

The results of ego-nets and action nets enabled us to visualize graphically the differences and similarities across interviewees, not only in terms of the number or diversity of collaborators (alters), but also via the practices they perform with them. The number of alters associated with each interviewee ranged from 4 to 30 . Some interviewees only reported one kind of collaborator (e.g., civil society, academia, etc.), whereas others had a varied spectrum of collaborators, and the interviewees also reported collaborations with alters working at different scales (i.e., local, regional, federal, or international). The number of collaborators that belong to civil society was significantly higher compared to that of academia and government. The least represented areas of collaborators were those from private initiative and for-profit organizations (Fig. 5).

Fig. 5. Number of collaborators (alters) per sector of work.

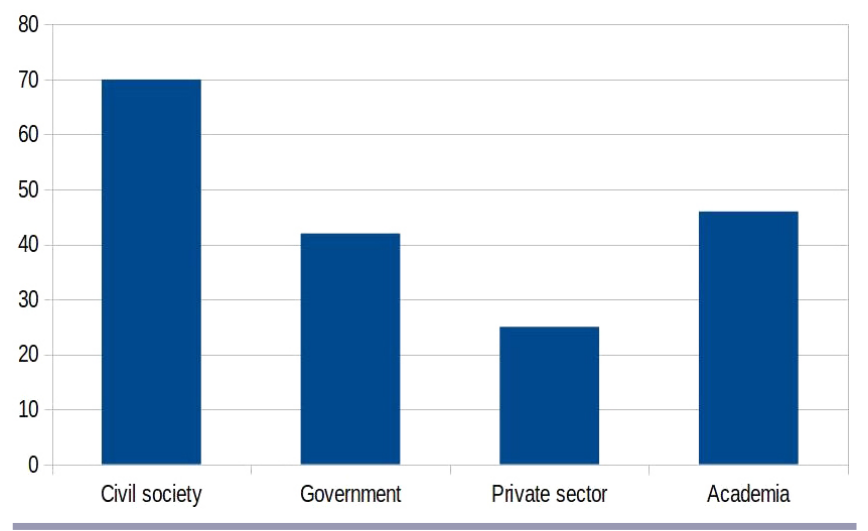

Egos and alters were engaged in 216 practices grouped into 20 categories of activities (see https://github.com/sostenibilidadunam/tlabs/blob/master/data/practices.csv for the complete list of activities). Eight of these categories received the majority of collaborative efforts (i.e., practices in which $>10$ alters are involved). Moreover, only eight alters participated in 16 categories 
Fig. 6. Network of categories of practices (brown) and alters (blue). Triangles indicate categories of practices in which there is high participation of alters.

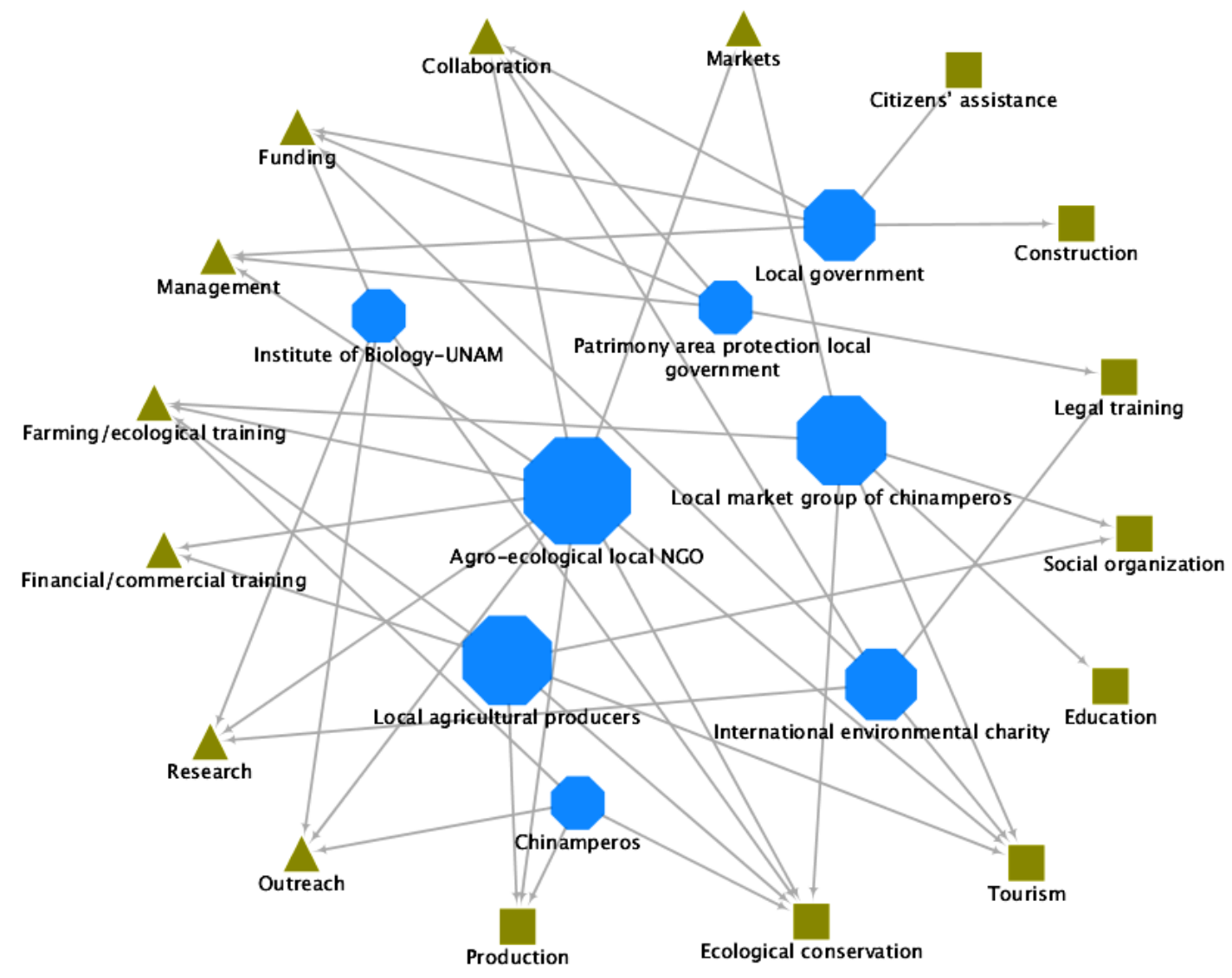

of practices (including the eight mentioned previously; Fig. 6). These alters are the ones with the widest diversity of activity engagement.

\section{Agents' problem space}

Our analysis of cognitive maps revealed which system elements and connections were shared with other interviewees and which elements were particular to each interviewee's description of the SES. Those aspects of the cognitive map that are unique to specific interviewees are particularly illustrative of their interpretation of the system. We used the specific articulation of variables and their prominence according to their position in the cognitive map to identify the participant with a narrative of the system. For example, interviewees TL004 and TL007 were categorized with "urbanization"; however, TL004 conceptualized the degradation of Xochimilco as a problem of uncontrolled population growth, lack of job opportunities, water scarcity, and lack of citizen actions that impact and lead to public health issues and the abandonment of chinampas. In contrast, TL007 conceptualized the problem as one of immigration to the area, chinampas urbanization, and water pollution, and these factors as having an impact on the quality of the soil and on the abandonment of chinampas. The cognitive map analysis thus permitted an exploration of how interviewees conceptualized the system differently, and how these differences relate to their individual agent profiles.

We identified two common meta-narratives related to the degradation of Xochimilco. These two meta-narratives revealed that although the perception of degradation was prevalent among the individual interviewees, degradation is not limited to its ecological expression, but includes social and cultural degradation as well.

We characterized the first and most complex meta-narrative in terms of its variables, which we called "urbanization" (or Urban). According to the elements connected in the meta-narrative, the notion of urbanization involved several central processes such as population growth, farmers' abandonment of chinampas, and urbanization of chinampas. These processes affect each other in a way in which farmers' abandonment of chinampas creates conditions for the chinampas to be urbanized by new settlers searching for new land because of the imbalanced ratio of population growth and decreased space for building houses. In the view of the participants, these three central processes create a particular context that is further influenced by other concepts such as the loss of Xochimilco's traditional cultural values and its subsequent effect on the younger generations' lack of interest in farming. These latter relationships in the narrative are 
Table 2. Four perspectives that emerged from the $\mathrm{Q}$ method factor analysis as determined by statistical analysis of interviewees statement alignment.

\begin{tabular}{|c|c|c|c|}
\hline $\begin{array}{l}\text { Factor and } \\
\text { interviewee number }\end{array}$ & Value & Statements that distinguish each factor & Statement category \\
\hline Factor 1 & +4 & 2. Chinampas land use should be exclusively for agriculture & Land use and property rights \\
\hline $\begin{array}{l}\text { Interviewee: } 001 \text {, } \\
002,007,009,010 \text {, } \\
016,018,019\end{array}$ & 0 & $\begin{array}{l}\text { 25. People who are not native to Xochimilco are problematic because they } \\
\text { do not know anything about it or do not care }\end{array}$ & Patrimony, identity, and values \\
\hline Factor 2 & +4 & 4. The chinampa represents the patrimony of all Mexicans & Patrimony, identity, and values \\
\hline \multirow[t]{2}{*}{$\begin{array}{l}\text { Interviewee: } 006 \text {, } \\
008,015\end{array}$} & +2 & $\begin{array}{l}\text { 10. Xochimilco festivities should be preserved, as they are part of Mexico's } \\
\text { history }\end{array}$ & Patrimony, identity, and values \\
\hline & -1 & 12. Xochimilco as a priority site for biodiversity conservation is overrated & Patrimony, identity, and values \\
\hline Factor 3 & 0 & 6. The chinampa is an important element of Xochimilco identity & Patrimony, identity, and values \\
\hline \multirow[t]{3}{*}{$\begin{array}{l}\text { Interviewee: 004, } \\
014,017\end{array}$} & 0 & $\begin{array}{l}\text { 17. It is possible to convert chinampas land use to urban without degrading } \\
\text { Xochimilco lake }\end{array}$ & Land use and property rights \\
\hline & +3 & $\begin{array}{l}\text { 18. Agricultural use of the chinampas is affecting the ecology of } \\
\text { Xochimilco lake }\end{array}$ & Ecological conditions and stressors \\
\hline & +3 & 23. It is important to bless the chinampas and their agricultural products & Patrimony, identity, and values \\
\hline $\begin{array}{l}\text { Factor } 4 \\
\text { Interviewee: }\end{array}$ & +1 & $\begin{array}{l}\text { 16. Lots of young people aspire to continue the traditional agricultural } \\
\text { practices in the chinampas }\end{array}$ & Livelihoods \\
\hline 005 & +2 & 19. The lake area of Xochimilco is in good ecological condition & Ecological conditions and stressors \\
\hline
\end{tabular}

particularly important because Xochimilco's identity, formed by tens of generations, has been grounded in farming. Related to the lack of interest in farming is the issue of reduced market opportunities for farm commodities. Regulated and unregulated settlements on the chinampas also play an important role in the urbanization meta-narrative. In this meta-narrative, it is clear that the interviewees understood that there is a positive feedback between new settlements on the chinampas (that, when first established, are unregulated) and farmers' abandonment of chinampas. This is not a minor issue because chinampas are part of the protected and conservation area. Finally, it was understood that the lack of action and absence of interest shown by both local government and civil society plays a role in the current situation. In summary, this urbanization narrative comprised three elements: (1) the loss of cultural values and farmers'identity of Xochimilco, (2) uncontrolled urban growth and the change in land use from farming to unregulated human settlements, and (3) lack of governance (from local government and civil society).

In the second meta-narrative, we identified that there was a relationship between "intensive farming practices" (or Agro) and the quality of soil and water. The meta-narrative demonstrated that the interviewees understood that intensive farming, especially when pesticides are used, has considerable impact on soil and water quality, biodiversity loss, and human health. Soil, water, biodiversity loss, and public health problems were not only attributed to intensive farming but, inevitably, were also linked to urbanization and land use changes.

In summary, the Urban and Agro meta-narratives were connected through issues of water, particularly through the concepts of water pollution, sewage discharge, and overexploitation of water bodies. Implicitly, the agency of the interviewees is reflected in these meta-narratives through the activities of farming, market engagement, tourism, and urbanization. Making these connections explicit implies that the interviewees' roles, responsibilities, values, and actions in shaping the SES's dynamics are made visible.

\section{Integrating agency network analysis}

The results from ANA were mapped into a single graph as a "hiveplot" (Fig. 7). The hiveplot shows the articulation of the ego-nets, action-nets, categories of practices, and meta-narratives. It allowed us to identify the most prominent alters in terms of their relation to both egos and practices, and most importantly, which categories of practices received the most collaborative efforts. When observing these categories in terms of the two metanarratives that emerged from the cognitive maps, we see that the categories of practices devoted to the area of Agro are double the number of categories of practices that correspond to the Urban meta-narrative.

\section{Agents' values systems}

The Q methodology analysis was performed with 15 participants (Q sorts), using 28 statements. The perspectives of the participants were represented by four factors (clusters of a "shared" vision). Certain statements distinguish each factor because they have statistically significant differences when factors are compared (Table 2). In general terms, the four perspectives that emerged from this analysis are: factor 1, chinampas for exclusive agricultural use; factor 2, chinampas as a Mexican crucial patrimony; factor 3, current agricultural practices affect the ecological condition of the wetland, and religious beliefs are important for chinampas agriculture; and factor 4, the wetland is in a good ecological condition, and young people still aspire to continue the agricultural chinampa practices. However, because factor 4 has only one participant, the statements that distinguish that factor from the others are not the statements with higher values; thus, this participant most agrees $(+4)$ with the statement, "All inhabitants and visitors of Xochimilco must keep the area clean," and most disagrees (-4) with, "It is possible to convert the land use of chinampas to urban without degrading the Xochimilco lake."

The analysis also provided information regarding which of the normative statements received the greatest consensus among interviewees and thus indicated where there appears to be 
Fig. 7. Articulation of ego and action networks with the meta-narratives from cognitive maps. Egos and alters axes: yellow $=$ civil society, blue $=$ academia, green $=$ government, purple $=$ private sector. Practices axis: practices are clustered by category and ordered by in-degree; squares = Urban meta-narrative, circles = Agro meta-narrative, superimposed squares and circles $=$ both Urban and Agro.

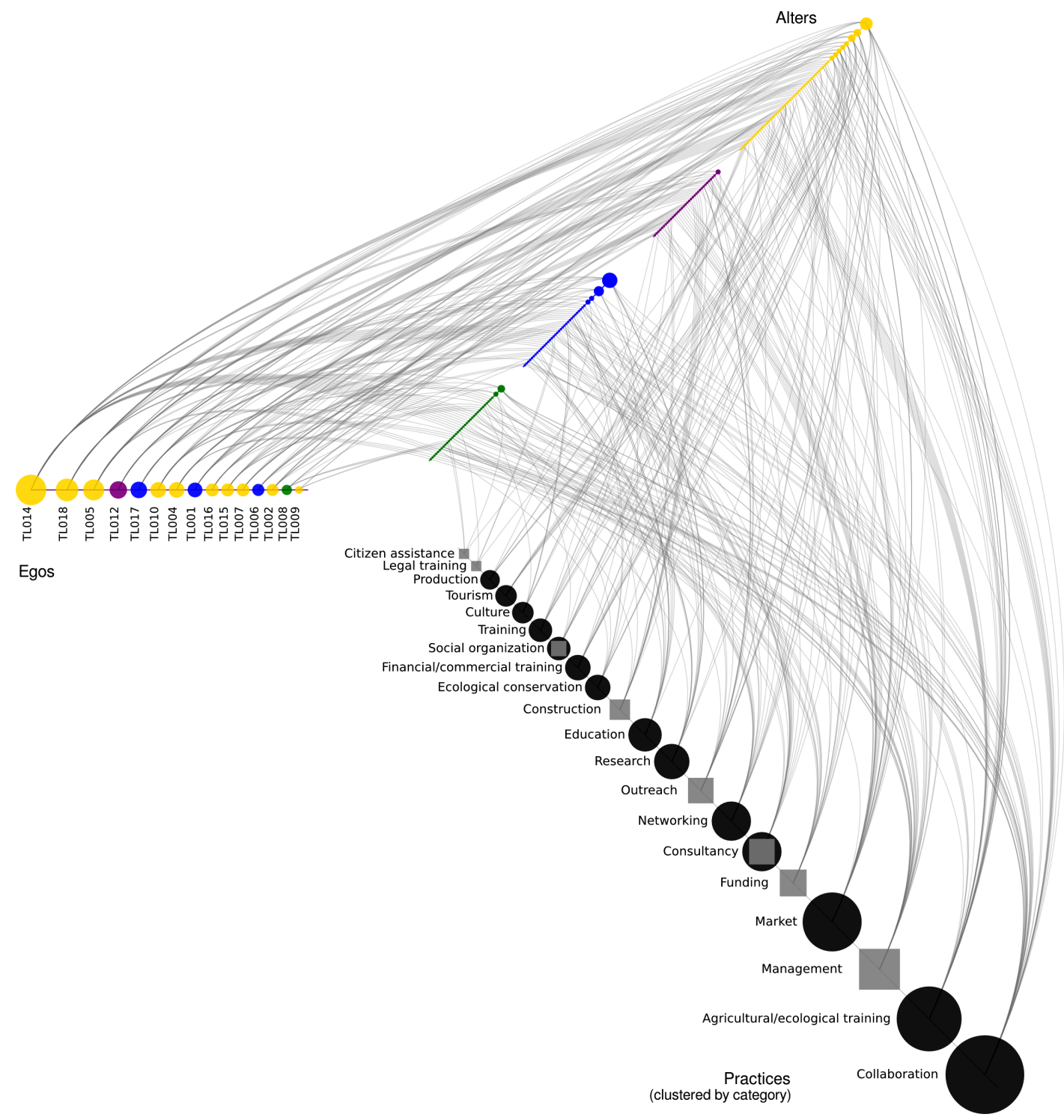

common ground or widely shared perspectives among those interviewed. In our case, the statement most frequently chosen by participants to be given a value of +4 was, "Urbanization is destroying Xochimilco," and the one chosen most frequently with a value of -4 was, "The lake area of Xochimilco is in a good ecological condition."

The following example illustrates how the information extracted with the different instruments forms the profile of an agent. Interviewee TL001 is an agent who has worked mainly in two different worlds (academic and nongovernmental) by developing capacity-building projects in water quality analysis for chinamperos. The social network analysis showed that this agent's social action arena consists of social capital that mainly revolves around these types of practices (practices through which the ego connects academia with civil society), a role that has the potential to act as a strong link between these groups as an intermediary for communication and as a monitor of the SES. The narrative derived from the agent's cognitive map falls within the category of Agro-ecological/water, and the agent located itself acting on issues related to agricultural practices but would like to work in urbanization topics (and found urbanization as one of the most crucial problems in the system). Furthermore, interviewee TL001 belongs to a group (factor 1 in the Q methodology) in which issues of concerns are the ones that matter the most to local inhabitants and chinamperos, particularly issues about biodiversity, urbanization, degradation of the ecosystem, and the chinampa as a core element of the Xochimilco system. 


\section{DISCUSSION}

Here, we have described a suite of tools and approaches to elucidate agency in terms of personal and shared perspectives, values, and practices, and common narratives relating the individual to the social and political processes that drive system dynamics. Although some of the methodological tools we used are not new, our intention was to employ and articulate them in a novel way to capture the different facets of potentially transformative agents. The approach we have described here was designed: (1) to identify and describe the types of potential agents of change in a specific context and system, (2) to identify the different visions of a system from the agents' perspectives, (3) to identify the space of action of the agents and the redundancy or gaps in their action routes, and (4) to develop both a baseline from which potential change can be observed and an input for the design of a transformative space intended to generate collective agency. Ultimately, our aim was to depict the place of the individual within processes of broader system transformation.

As part of the mixed set of methods, we found that ANA was useful in identifying interviewees' space of action, their resources, and social relationships that the interviewee draws on to act in these spaces. In other words, ANA was instrumental in describing how and where each agent is acting within the system. Coupling ANA with Q methodology provided a more detailed understanding of the profile of each agent because it elicited the main motivations behind the agents' actions (i.e., whether to act in a certain way but not in another) in the space of action. Thus, we were not only capturing what people were doing, where, and with whom, but were also getting some insights into why, or in the case of actions that did not correspond to the values expressed by the interviewee, where disjuncture exists that requires further exploration with the interviewee as a potential topic for reflection and learning. We consider this combined method to provide a fair but concise description of the participant as an agent in its context. Furthermore, ANA plus Q methodology helped us to ensure that participants in the T-lab had different capacities and social networks related to Xochimilco. By bringing diverse and potentially complementary skills and connections to the T-lab, we hope to create conditions in which novel interactions might evolve as the project continues.

Although most of the interviewees (egos) have similarities in their social networks with respect to sharing collaborators (alters), when articulating the results of ANA, we identified a low degree of collaboration among the participants we interviewed because few of the practices they reported were shared with more than one collaborator, even though they reported engaging in similar types of practices. Furthermore, when analyzing the metanarratives that emerged from the cognitive maps, it was clear that the system variables the interviewees perceived as the most important (i.e., urban issues) often did not match the most common practices in which they were engaging (i.e., agricultural). These results suggest that there is redundancy among the networks because agents might be "trapped" in the same loop of action. This analysis thus gave us information in support of our hypothesis: although several agents are engaged in similar practices within the area, the collaboration among them is not sufficient to affect the issues they perceive as most urgent according to their cognitive maps and Q sorts.
Responding to the many concerns expressed in participatory development literature (e.g., Kothari 2001, Williams 2004; Whitehead and Gray-Molina, unpublished manuscript, http:// siteresources.worldbank.org/INTPOVERTY/Resources/WDR/DfiDProject-Papers/whitehea.pdf), we also found that this approach allowed us to capture multiple ego-centric (interviewee-centric) viewpoints on a system prior to engaging in any collective process that might unintentionally exacerbate or reproduce existing social power dynamics or silence particular voices. To create the imagined possibilities of emancipatory spaces and processes and the potential for political agency and change, there is a need to engage with individuals and their aspirations and values (Brown and Westaway 2011, Walker 2018). Our approach provided a sort of "boundary object," i.e., a series of maps, that reflected, albeit abstractly, the interviewees' social and ecological reality in a novel way. By capturing each interviewee's world and worldview independently, we aimed to ensure that all voices we engaged with were represented fully and as accurately as possible. The actions, beliefs, and capacities of some individuals would have inevitably remained hidden to us, and perhaps to themselves, if they had simply engaged in a collective process without having had the opportunity to reflect on their individual agency. Second, if, as the literature increasingly recognizes (O'Brien 2012, O'Brien and Sygna 2013, Pelling et al. 2015), system transformation must have roots in cognitive and psychological change, the approach of transformative design must engage the personal and explicitly link personal profiles to the SES. Thus, participants' information, as agents, is the foundation for creating a cognitively and emotionally meaningful space (Colombetti and Krueger 2015). Thus, for a group of individuals to develop collective agency, they must first understand and materialize their own individual agency in the system in which they are embedded (O'Brien and Sygna 2013, Pesch 2015).

The ultimate objective of our transformative space is to create conditions from which collective agency can emerge. From our perspective, a transformative space is first a safe space, which, according to Pereira et al. $(2015: 6035,6038)$, is a collaborative milieu in which to "[...] freely express different views, opinions and beliefs," while "[...] recognising the opportunities associated with pluralising knowledge systems as a stepping stone towards enacting SETs (social-ecological transformations)," and it is "[..] fundamentally not only about the deliberation and enactment of 'sustainable' transformations, but also equally about 'just' transformations based on greater community understanding, equality and justice." Under this conceptual umbrella, the aim of our transformative space would be to create a process through which we could achieve construction of meaningful social relationships through the emergence of shared values, problem reframing and reflexivity, and discovery of different (new) pathways for change.

The initial phase of the T-lab provides a foundation for these objectives. The construction of meaningful social relationships through the emergence of shared values can be promoted by using $\mathrm{Q}$ methodology. The $\mathrm{Q}$ method illustrates where there is convergence in values among disparate individuals, even prior to any social interaction. It also illustrates where perspectives and values may be most divergent. Furthermore, the results from the cognitive maps provide inputs that can be used in later stages of the T-lab to help design activities to promote empathy, an essential 
component of collective agency (e.g., Groch et al. 2012, Wald et al. 2017). The cognitive maps illustrate how individuals are positioned within a suite of particular system interactions and dynamics; these insights can be used as entry points to see the same system from points of view of other agents.

Collective problem reframing, which is also an ambition of many exercises for transformative change, is also facilitated by the methods described here. Cognitive maps and Q methodology offer a baseline that define the starting point from which initial visions can be explored and reframed through activities that foster reflexivity. In later stages of the T-lab process, different participants have invited each other to "enter their world" so that they can have a direct experience of the conditions in which they live and act, for example, farming the chinampa or living in an informal settlement at the edge of the wetland. These experiences, embodying the cognitive maps and Q sorts of the interviewees, serve to bring new agents into the personal worlds of each interviewee, can potentially help to change preconceived ideas about what the problems are, and can also help participants to think differently about how others experience and conceptualize their relationships with the environment.

Discovering new pathways for change is, perhaps, the most aspirational but also most essential outcome of any deliberative transformative process. In this initial phase of the T-lab, we aimed to help individuals link what they do in the system to what they value and what they perceive as the most problematic about the system in which they act. Because the ego and action networks illustrate capacities of individuals and link these capacities to practices and to other people (alters), these networks illustrate existing pathways in which individuals are engaged. Collectively, the number, type, and scale of influence of the alters associated with the interviewees provides the basis for speculation on the possible pathways and networks through which change could occur and how agency could grow in conjunction with the T-lab process. If the agents acknowledge that their actions are not resulting in the change they desire, the aggregation of their networks (as shown in the hiveplot) can help to illustrate potential gaps, redundancies, or dominant practices in their activities that could be targeted for collective action.

In our case, we found that the meta-narratives that emerged from the aggregation of the cognitive maps and the dominant practices in which the agents were engaged were incongruent. Although the narrative focused on Urban, the practices focused on Agro, potentially illustrating how the interviewees' social interactions are not involving agents with specific practices within the urban space, despite the fact that they are dominantly concerned with elements of the urban narrative in system degradation. The aggregated cognitive map and its interpretation can thus help the agents to explore what they need for transformation to happen. As others have observed, requesting that participants envision alternative regimes without explicitly discussing pathways, collaborative action partnerships, and resources to support agency that promotes the development of those new regimes will stifle the success of bottom-up, transformative interventions and spaces (Stirling 2008).

\section{CONCLUSION}

In Xochimilco, economic resources are scarce, the attention of public sector agents is often contingent on political agendas and opportunities, and collaboration is challenged by the diversity of interests involved. We departed from a premise that change must originate from within each actor engaged in transformative processes. This is not because residents, individually, must bear the responsibility for initiating and implementing transformative pathways, but rather because without their acknowledgement of their agency and capacity (and their limits), transformation is unlikely to occur. The diverse agents in this SES have different experiences of the place, i.e., some are organic farmers, others come from irregular settlements, and others are from traditional neighborhoods, but all feel that they belong to the same place, Xochimilco. It is through investing in meaningful relationships among these diverse agents that the process of reframing what the problems are in Xochimilco can begin to take place.

We described the relevance of agency for transformation processes and how our approach may foster collective agency as we encourage individuals' agency. We suggest that our methodological approach for phase 1 may be instrumental in identifying individual agency and lay a foundation on which to build collective agency by recognizing shared values and meanings around which possible transformative interventions can be designed. Hence, it is by having access to the issues that the participants value the most that we can have an indicator of what the participants believe to be good or bad for the system. This information provides all those involved with a more transparent framework through which they can make meaningful decisions aligned with what transformation towards sustainability implies for their context. In turn, this knowledge may guide possible new collective actions through agent-developed mechanisms that will constitute a transformed space of action.

Through this approach, we posit that the initial phases toward a transformation can be convened when new relationships and alliances are formed, new ways of conceptualizing the SES and the positions of agents in it arise, and new social capitals are envisaged. Therefore, the transformation we focus on is manifested in different spaces of actions framed under the emergent system of shared values.

Responses to this article can be read online at: http://www.ecologyandsociety.org/issues/responses. $\mathrm{php} / 10214$

\section{Acknowledgments:}

We greatly appreciate and thank all the Xochimilco T-lab participants for their valuable time, effort, and interest in sharing their experiences and knowledge throughout the process. We acknowledge the work of the following students: Patricia PérezBelmont for developing the $Q$ method analysis; Beatriz Ruizpalacios for support in logistics, data gathering, and design of the T-lab process; and Yutzil Castán for support in data organization and analysis. We also thank Rodrigo Garcia-Herrera, academic technician at LANCIS-IE-UNAM, for writing the programs to upload the databases and generate the hiveplot (https:/I github.com/sostenibilidad-unam/tlabs/tree/master/hiveplot). This work is based on research supported in part by the Transformations to Sustainability programme, which is coordinated by the 
International Social Science Council and funded by the Swedish Development Cooperation Agency (Sida), and implemented in partnership with the National Research Foundation of South Africa. The Transformations to Sustainability Programme represents a contribution to Future Earth. This study has been developed in the North America Sustainability Hub, hosted by Arizona State University (ASU) working in partnership with the National Laboratory for Sustainability Sciences (LANCIS), housed at the National Autonomous University of Mexico (UNAM). It is part of the STEPS Pathways to Sustainability Global Consortium (https://steps-centre.org/globall). This work was supported by the project PAPIIT-DGAPA-UNAM IA301117, and the material is also based on work supported by the National Science Foundation under Grant 1414052, CNH: The Dynamics of Multi-Scalar Adaptation in Megacities (PI H. Eakin). Any opinions, findings, conclusions, or recommendations expressed in this material are those of the author $(s)$ and do not necessarily reflect the views of the National Science Foundation. We also acknowledge the InterAmerican Institute for Global Change Research (IAI) for supporting the MEGADAPT project: Collaborative Research Network-CRN3: "Coping with hydrological risk in megacities: Collaborative planning framework for the Mexico City Metropolitan Area" (Project CNR3108; http://www.iai.intl? page id=2031). Finally, the first author extends acknowledgment to the PhD Program in Sustainability Sciences, UNAM "Doctorado en Ciencias de la Sostenibilidad, Universidad Nacional Autónoma de México."

\section{LITERATURE CITED}

Abson, D. J., J. Fischer, J. Leventon, J. Newig, T. Schomerus, U. Vilsmaier, H. von Wehrden, P. Abernethy, C. D. Ives, N. W. Jager and D. J. Lang. 2017. Leverage points for sustainability transformation. Ambio 46(1):30-39. http://dx.doi.org/10.1007/ s13280-016-0800-y

Barandiaran, X. E., E. Di Paolo, and M. Rohde. 2009. Defining agency: individuality, normativity, asymmetry, and spatiotemporality in action. Adaptive Behavior 17(5):367-386. http://dx. doi.org/10.1177/1059712309343819

Barkin, D. 1998. Sustainability: the political economy of autonomous development. Organization and Environment 11 (1):5-32. http://dx.doi.org/10.1177/0921810698111001

Bourdieu, P. 1977. Outline of a theory of practice. Cambridge University Press, Cambridge, UK.

Brown, K., and E. Westaway. 2011. Agency, capacity, and resilience to environmental change: lessons from human development, well-being, and disasters. Annual Review of Environment and Resources 36:321-342. http://dx.doi.org/10.1146/ annurev-environ-052610-092905

Brown, S. R. 1986. Q technique and method: principles and procedures. Pages 57-76 in W. D. Berry and M. S. Lewis-Beck, editors. New tools for social scientists: advances and applications in research methods. Sage, Beverly Hills, California, USA.

Colombetti, G., and J. Krueger. 2015. Scaffoldings of the affective mind. Philosophical Psychology 28(8):1157-1176. http://dx.doi. org/10.1080/09515089.2014.976334
Crossley, N., E. Bellotti, G. Edwards, M. G. Everett, J. Koskinen, and M. Tranmer. 2015. Social network analysis for ego-nets: social network analysis for actor-centrednetworks. Sage, Thousand Oaks, California, USA.

Di Paolo, E. A., T. Buhrmann, and X. E. Barandiaran. 2017. Sensorimotor life: an enactive proposal. Oxford University Press, Oxford, UK.

Diani, M., and D. McAdam, editors. 2003. Social movements and networks: relational approaches to collective action. Oxford University Press, Oxford, UK.

Dorado, S. 2005. Institutional entrepreneurship, partaking, and convening. Organization Studies 26(3):385-414. http://dx.doi. org/10.1177/0170840605050873

Eakin, H., A. M. Lerner, D. Manuel-Navarrete, B. H. Aguilar, A. Martínez-Canedo, B. Tellman, L. Charli-Joseph, R. Fernández Álvarez, and L. Bojórquez-Tapia. 2016. Adapting to risk and perpetuating poverty: household's strategies for managing flood risk and water scarcity in Mexico City. Environmental Science and Policy 66:324-333. http://dx.doi.org/10.1016/j.envsci.2016.06.006

Emirbayer, M., and A. Mische. 1998. What is agency? American Journal of Sociology 103(4):962-1023. https://doi.org/10.1086/231294

Giddens, A. 1984. The constitution of society: outline of the theory of structuration. University of California Press, Los Angeles, California, USA.

Groch, K., K. E. Gerdes, E. A. Segal, and M. Groch. 2012. The grassroots Londolozi model of African development: social empathy in action. Journal of Community Practice 20 (1-2):154-177. http://dx.doi.org/10.1080/10705422.2012.644207

Hassan, Z. 2014. The social labs revolution: a new approach to solving our most complex challenges. Berrett-Koehler, Oakland, California, USA.

Heras, M., and J. D. Tàbara. 2014. Let's play transformations! Performative methods for sustainability. Sustainability Science 9 (3):379-398. http://dx.doi.org/10.1007/s11625-014-0245-9

Karpouzoglou, T., L. Pereira, P. Olsson, and N. Frantzeskaki, editors. 2018. Designing transformative spaces for sustainability in social-ecological systems. Ecology and Society SF134. [online] URL: https://www.ecologyandsociety.org/issues/view.php?sf=134

Kothari, U. 2001. Power, knowledge and social control in participatory development. Pages 139-152 in B. Cooke and U. Kothari, editors. Participation: the new tyranny? Zed Books, London, UK.

Lade, S. J., L. J. Haider, G. Engström, and M. Schlüter. 2017. Resilience offers escape from trapped thinking on poverty alleviation. Science Advances 3(5):e1603043. http://dx.doi. org/10.1126/sciadv. 1603043

Laland, K. N., and M. J. O'Brien. 2011. Cultural niche construction: an introduction. Biological Theory 6(3):191-202. http://dx.doi.org/10.1007/s13752-012-0026-6

Leach, M., J. Rockström, P. Raskin, I. Scoones, A. C. Stirling, A. Smith, J. Thompson, E. Millstone, A. Ely, E. Arond, C. Folke, and P. Olsson. 2012. Transforming innovation for sustainability. 
Ecology and Society 17(2):11. http://dx.doi.org/10.5751/ ES-04933-170211

Manuel-Navarrete, D. 2015. Double coupling: modeling subjectivity and asymmetric organization in social-ecological systems. Ecology and Society 20(3):26. http://dx.doi.org/10.5751/ ES-07720-200326

Manuel-Navarrete, D., and C. N. Buzinde. 2010. Socio-ecological agency: from 'human exceptionalism' to coping with 'exceptional' global environmental change. Pages 136-149 in M. R. Redclift an G. Woodgate, editors. The international handbook of environmental sociology. Second edition. Edward Edgar, London, UK. http://dx.doi.org/10.4337/9781849805520.00018

Manuel-Navarrete, D., and M. Pelling. 2015. Subjectivity and the politics of transformation in response to development and environmental change. Global Environmental Change 35:558-569. http://dx.doi.org/10.1016/j.gloenvcha.2015.08.012

Maru, Y. T., C. S. Fletcher, and V. H. Chewings. 2012. A synthesis of current approaches to traps is useful but needs rethinking for indigenous disadvantage and poverty research. Ecology and Society 17(2):7. http://dx.doi.org/10.5751/ES-04793-170207

Mazari-Hiriart, M., S. Ponce-de-León, Y. López-Vidal, P. IslasMacías, R. I. Amieva-Fernández, and F. Quiñones-Falconi. 2008. Microbiological implications of periurban agriculture and water reuse in Mexico City. Plos One 3(5):e2305. http://dx.doi. org/10.1371/journal.pone.0002305

McLaughlin, P., and T. Dietz. 2008. Structure, agency and environment: toward an integrated perspective on vulnerability. Global Environmental Change 18(1):99-111. http://dx.doi. org/10.1016/j.gloenvcha.2007.05.003

Moctezuma, P. 2001. Community-based organization and participatory planning in south-east Mexico City. Environment and Urbanization 13(2):117-133 http://dx.doi.org/10.1177/09562$\underline{4780101300209}$

Mohan, G., and K. Stokke. 2000. Participatory development and empowerment: the dangers of localism. Third World Quarterly 21 (2):247-268. http://dx.doi.org/10.1080/01436590050004346

Moore, M.-L., O. Tjornbo, E. Enfors, C. Knapp, J. Hodbod, J. A. Baggio, A. Norström, P. Olsson, and D. Biggs. 2014. Studying the complexity of change: toward an analytical framework for understanding deliberate social-ecological transformations. Ecology and Society 19(4):54. http://dx.doi.org/10.5751/ ES-06966-190454

Moore, M.-L., and F. Westley. 2011. Surmountable chasms: networks and social innovation for resilient systems. Ecology and Society 16(1):5. http://dx.doi.org/10.5751/ES-03812-160105

O’Brien, K. 2012. Global environmental change II: from adaptation to deliberate transformation. Progress in Human Geography 36(5):667-676. http://dx.doi.org/10.1177/0309132511425767

O’Brien, K., and L. Sygna. 2013. Responding to climate change: the three spheres of transformation. Pages 16-23 in Proceedings: transformation in a changing climate: international conference in Oslo 19-21 June 2013. University of Oslo, Oslo, Norway. [online] URL: http://www.sv.uio.no/iss/english/research/news-and-events/ events/conferences-and-seminars/transformations/proceedingstransformation-in-a-changing-climate interactive.pdf
Olsson, P., V. Galaz, and W. J. Boonstra. 2014. Sustainability transformations: a resilience perspective. Ecology and Society 19 (4):1. http://dx.doi.org/10.5751/ES-06799-190401

Ostrom, E. 2000. Collective action and the evolution of social norms. Journal of Economic Perspectives 14(3):137-158. [online] URL: http://www.jstor.org/stable/2646923

Ostrom, E. 2009. A general framework for analyzing sustainability of social-ecological systems. Science 325 (5939):419-422. http://dx.doi.org/10.1126/science.1172133

Pahl-Wostl, C. 2002. Towards sustainability in the water sector the importance of human actors and processes of social learning. Aquatic Sciences 64(4):394-411. http://dx.doi.org/10.1007/ $\underline{\mathrm{PL} 00012594}$

Pahl-Wostl, C., M. Craps, A. Dewulf, E. Mostert, D. Tabara, and T. Taillieu. 2007. Social learning and water resources management. Ecology and Society 12(2):5. http://dx.doi. org/10.5751/ES-02037-120205

Pelling, M., K. O'Brien, and D. Matyas. 2015. Adaptation and transformation. Climatic Change 133(1):113-127. http://dx.doi. org/10.1007/s10584-014-1303-0

Pereira, L., T. Karpouzoglou, S. Doshi, and N. Frantzeskaki. 2015. Organising a safe space for navigating social-ecological transformations to sustainability. International Journal of Environmental Research and Public Health 12(6):6027-6044. http://dx.doi.org/10.3390/ijerph120606027

Pesch, U. 2015. Tracing discursive space: agency and change in sustainability transitions. Technological Forecasting and Social Change 90(B):379-388. http://dx.doi.org/10.1016/j.techfore.2014.05.009

Stern, P. C., and T. Dietz. 1994. The value basis of environmental concern. Journal of Social Issues 50(3):65-84. http://dx.doi. org/10.1111/j.1540-4560.1994.tb02420.x

Stirling, A. 2008. "Opening up" and "closing down": power, participation, and pluralism in the social appraisal of technology. Science, Technology, and Human Values 33(2):262-294. https://doi. org/10.1177/0162243907311265

Tschakert, P., P. J. Das, N. S. Pradhan, M. Machado, A. Lamadrid, M. Buragohain, and M. A. Hazarika. 2016. Micropolitics in collective learning spaces for adaptive decision making. Global Environmental Change 40:182-194. http://dx.doi.org/10.1016/j. gloenvcha.2016.07.004

Van der Walt, J. S., A. A. K. Buitendag, J. J. Zaaiman, and J. J. van Vuuren. 2009. Community living lab as a collaborative innovation environment. Issues in Informing Science and Information Technology 6:421-436. https://doi.org/10.28945/1070

Vänninen, I., M. Pereira-Querol, and Y. Engeström. 2015. Generating transformative agency among horticultural producers: an activity-theoretical approach to transforming integrated pest management. Agricultural Systems 139:38-49. http://dx.doi.org/10.1016/j.agsy.2015.06.003

Wald, D. M., E. A. Segal, E. W. Johnston, and A. Vinze. 2017. Understanding the influence of power and empathic perspectivetaking on collaborative natural resource management. Journal of Environmental Management 199:201-210. http://dx.doi.org/10.1016/ j.jenvman.2017.05.030 
Walker, M. 2018. Political agency and capabilities formation through participatory action research. Journal of Human Development and Capabilities 19(1):53-69. http://dx.doi. org/10.1080/19452829.2017.1392934

Webler, T., S. Danielson, and S. Tuler. 2009. Using $Q$ method to reveal social perspectives in environmental research. Social and Environmental Research Institute, Greenfield, Massachusetts, USA. [online] URL: https://www.betterevaluation.org/en/ resources/guide/using_Q_method_to reveal_social_perspectivesin environmental research

Westley, F., P. Olsson, C. Folke, T. Homer-Dixon, H. Vredenburg, D. Loorbach, J. Thompson, M. Nilsson, E. Lambin, J. Sendzimir, B. Banerjee, V. Galaz, and S. van der Leeuw. 2011. Tipping toward sustainability: emerging pathways of transformation. Ambio 40 (7):762-780. http://dx.doi.org/10.1007/s13280-011-0186-9

Westley, F. R., O. Tjornbo, L. Schultz, P. Olsson, C. Folke, B. Crona, and Ö. Bodin. 2013. A theory of transformative agency in linked social-ecological systems. Ecology and Society 18(3):27. http://dx.doi.org/10.5751/ES-05072-180327

Wigle, J. 2010. The "Xochimilco model" for managing irregular settlements in conservation land in Mexico City. Cities 27 (5):337-347. http://dx.doi.org/10.1016/j.cities.2010.04.003

Wigle, J. 2014. The 'graying' of 'green' zones: spatial governance and irregular settlement in Xochimilco, Mexico City. International Journal of Urban and Regional Research 38 (2):573-589. https://doi.org/10.1111/1468-2427.12019

Williams, G. 2004. Evaluating participatory development: tyranny, power and (re)politicisation. Third World Quarterly 25 (3):557-578. http://dx.doi.org/10.1080/0143659042000191438

Wood, G. 2003. Staying secure, staying poor: the "Faustian bargain". World Development 31(3):455-471. http://dx.doi. org/10.1016/S0305-750X(02)00213-9

Zabala, A. 2014. qmethod: a package to explore human perspectives using Q methodology. R Journal 6(2):163-173. [online] URL: https://journal.r-project.org/archive/2014/RJ-2014-032/ RJ-2014-032.pdf

Zambrano, L., V. Contreras, M. Mazari-Hiriart, and A. E. ZarcoArista. 2009. Spatial heterogeneity of water quality in a highly degraded tropical freshwater ecosystem. Environmental Management 43(2):249-263. http://dx.doi.org/10.1007/s00267-008-9216-1 